\title{
Carbonyl compounds indoors in a changing climate
}

\author{
Peter Brimblecombe and Carlota M Grossi
}

\begin{abstract}
Background: Formic acid, acetic acid and formaldehyde are important compounds in the indoor environment because of the potential for these acids to degrade calcareous materials (shells, eggs, tiles and geological specimens), paper and corrode or tarnish metals, especially copper and lead. Carbonyl sulfide tarnishes both silver and copper encouraging the formation of surface sulfides.

Results: Carbonyls are evolved more quickly at higher temperatures likely in the Cartoon Gallery at Knole, an important historic house near Sevenoaks in Kent, England where the study is focused. There is a potential for higher concentrations to accumulate. However, it may well be that in warmer climates they will be depleted more rapidly if ventilation increases.
\end{abstract}

Conclusions: Carbonyls are likely to have a greater impact in the future.

\section{Background}

Air pollutants are harmful to objects on display. This has long been recognised and even Homer described the damage to metals indoors when Odysseus returned to his home on Ithaca and found his weapons damaged:

(My son! we must remove and safe dispose All these my well-forged implements of war; And should the suitors, missing them, enquire Where are they? thou shalt answer smoothly thusI have convey'd them from the reach of smoke, For they appear no more the same which erst Ulysses, going hence to Ilium, left,

So smirch'd and sullied by the breath of fire."

Translator: William Cowper

This classical example illustrates the impact that combustion derived pollutants have on indoor objects. There has been a long history of concern over these indoors. In coal burning London Michel Faraday helped advised on the problems that paintings in the new National Gallery might face through exposure to sulfur dioxide and coal smoke in the outdoor air.

\footnotetext{
* Correspondence: P.Brimblecombe@uea.ac.uk

School of Environmental Sciences, University of East Anglia, Norwich Research park, Norwich NR4 7TJ, UK
}

However, increasingly and especially as concentrations of the classical combustion derived pollutants decline it may not be these that are most critical for objects on display. Furthermore, the pollutants that are harmful to health are not necessarily the same as those that cause damage to art objects. Many indoor pollutants outgas from display materials or the objects themselves. Many objects are typically stored in cases, and some paintings in well-constructed frames, despite the contemporary interest in open display. Thus outgassing can be important as sources of exposure within tightly sealed museums cases.

Of these indoor pollutants, carbonyls (carboxylic acids, aldehydes and carbonyl sulfide are possibly the most critical in damaging objects although alongside these one would have to place particles, hydrogen sulfide (although not especially common), hydrogen peroxide and some larger organic molecules (e.g. Volent and Baer [1]). In addition to causing damage they can sometimes pose health risks especially the residual pesticides [2].

Formic acid and acetic acid are important compounds in the indoor environment because of the potential to degrade calcareous materials (shells, eggs, tiles and geological specimens). In the case of shells the process has long been known and is referred to as Byne's disease. Additionally acetic acid is relevant in damage to paper. The remodelling of Bankside Power Station by Herzog 
and de Meuron to create the Tate Modern led to considerable criticism in the media. Some regarded the interior with "... raw oak floors, slightly soiled from use" as inspired [3], but there was an outcry that a warning from the Tate's flooring contractor's over the dangers of using untreated oak had been ignored. Amid denials from the Gallery, conservators agreed that "that the floors could create acidic oak dust, one of the most corrosive forms of indoor pollution, and possibly damage some metals and ceramics" [4].

Formaldehyde has long been of concern because of its potential to cause damage as emphasised in the early booklet by Hatchfield and Carpenter [5], although as discussed by Raychaudhuri and Brimblecombe [6] it is possible that the actions of formaldehyde came about largely from its oxidation to formic acid on the surface of metals. A large amount of work has been done by the building industry concerning the emission of formaldehyde from furnishings, fabrics, foams and glues because of the regulatory pressures to keep the formaldehyde content of constructional and decorative materials at a low level [7] given fears that it may be a carcinogen. While not primarily aimed at museums these have helped lower emissions

Another important carbonyl compound is carbonyl sulfide [8]. Hydrogen sulfide has long been of concern in the museum environment because of its ability to tarnish metals, but it is possible that the sulfide emitted from furnishings is carbonyl sulfide, as shown in the case of wool where at ambient temperatures it is carbonyl sulfide rather than hydrogen sulfide that is emitted [9]. It is this that explains the ability of wool to tarnish metals such as copper and silver. Other materials containing sulfur, such as rubber are also important sources of carbonyl sulphide.

The changing climate in the 20th century has been much discussed. However, the changes that are likely go well beyond the temperature increases that features so widely in the media and in public perception. Pressures to reduce the amount of energy used in buildings has not only meant a greater level of insulation (hence the potential increase of emissions of indoor pollutants from novel materials), but also lowered air exchange rates. Lower exchange rates allow pollutants to accumulate indoors [10]. New materials are also in use indoors and within museum cases, but in the heritage sector increasing care is taken in the choice of display materials through the use of the Oddy test [11]. Indoors temperatures are likely to increase, perhaps in some environments due to a greater demand for comfort heating [12], although this may be countered by regulations over energy efficiency. In historic properties without active climate control temperatures are likely to rise because of the exchange of outside air with interiors [13,14].
The carbonyls relevant to the heritage environments are likely to respond in various ways to the changing temperature.

\section{Carboxylic acids}

Changing thermohygrometric climate is likely to affect the carboxylic acid loss from wood indoors. In the simplest sense this might be related to their increasing vapour pressure with temperature, but to fully account for this it would be important to take the water content, $\mathrm{pH}$ and the activity coefficient into account. However, these are likely to be second order effects on the vapour pressure in unheated historic interiors.

\section{Formaldehyde}

Changing temperatures are also likely to affect aldehyde concentrations. Xiong and Zhang [15] have examined the dependence of formaldehyde concentration on time in the static chamber measurements between $25^{\circ} \mathrm{C}$ and $50^{\circ} \mathrm{C}$. These experiments suggest that the flux rate and extent of loss of formaldehyde from building materials increases with temperature. However, the damage caused by formaldehyde is not necessarily dependent on its concentration, as much as its ability to be oxidized to formic acid [6]. It has been argued that increased concentrations of volatile organic compounds in outdoor air and longer sunlight hours might enhance ozone concentrations [16]. Were this ozone to be advected indoors it might lead to a more rapid production of formic acid from formaldehyde at metal surfaces.

\section{Carbonyl sulfide}

The release of carbonyl sulfide from wool is strongly dependent on temperature, probably because higher temperatures encourage degradation of cystine. Experiments with a range of woolen yarns suggest that changes between ambient $\left(\sim 20^{\circ} \mathrm{C}\right)$ and $50^{\circ} \mathrm{C}$ cause one to two orders of magnitude increase in the rate of loss of carbonyl sulfide [9]. Thus, increases in room temperature would have the potential to enhance indoor concentrations.

\section{Method}

In this section we explore the likely changes in indoor carbonyl concentrations as the result of future changes in temperature. We have chosen Knole, a National Trust property near Sevenoaks in Kent, as a site for our estimates. This historic house has an unheated interior and parts date back to the late medieval period. However, the interiors are largely of the early seventeenthcentury and our study will focus on the Cartoon Gallery. This is a long room containing important drawings, most particularly some early copies (1624) of Raphael's cartoons (Sackville-West, 1998). 
Daily temperature observations are available for Central England from the late 18th century as the Central England Temperature record, HadCET [17] and these can be tuned to the heritage climate at Knole [18]. The possible changes in future climate of the British Isles are available as high resolution outputs (UKCP09) that derive from the Hadley Model HadCM3 by downscaling with a weather generator to provide an increased resolution [19]. Climate models require emission scenarios and here we use output that comes from scenario A1F1 as it gives the largest changes and thus represents a type of worst-case. The scenarios make little difference to predictions of indoor climate in the near future, although beyond 2040 the highest predicted temperatures are associated with scenario A1F1 [14].

The UKCP09 output used in this research provided maximum and minimum temperatures and relative humidity on a daily basis for thirty year periods. The output consisted of a hundred different evaluations, essentially providing 3000 estimates of the daily weather conditions in each period. These thirty-year periods centre on 2025, 2035, 2045, 2055, 2065, 2075 and 2085 in addition to a baseline period centred on 1975. Daily average temperatures were calculated, in the conventional way, by taking the mean of the maximum and minimum temperature each day.

\section{Results and discussion}

The thermo-hygrometric conditions within the interior of Knole have been regularly monitored since 2000. However, such records cover a short timespan in comparison with the long history of the house and cannot tell us of likely future climate. A simple transfer function has been developed, which can be used to estimate the indoor thermo-hygrometric environment in the Cartoon Gallery from external conditions. The process (covered in detail in Lankester and Brimblecombe [13,14]) correlates daily indoor temperature and relative humidity with that of a nearby weather station using a simple regression equation and establishing different coefficients for each month to allow for seasonal climate and patterns of room use. This approach assumes the relationship between the interior and outdoors remains constant into the future, so is not robust against modifications to the building or its ventilation. The transfer coefficients for relative humidity indoors are calculated as specific humidity to conserve water during air movement [13,14]. Hindcasting the interior temperature in the Cartoon Gallery using the Central England Temperature record is possible at Knole [18]. The HadCET data were used to calculate daily indoor temperatures and expressed as medians of the annual means for the slightly overlapping 11 -year periods centred at 1785, 1795... through to 2005. This is shown in Figure 1, which gives both the outdoor

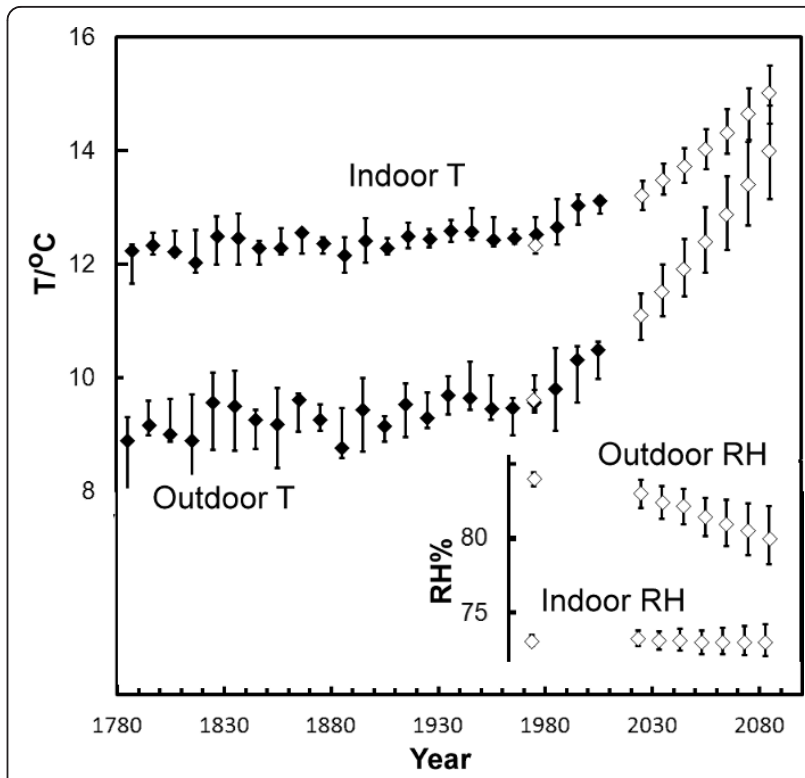

Figure 1 Median annual temperature outdoors and estimates for the Cartoon Gallery using HadCET (closed diamonds) and UKCP09 (open diamonds). At lower right: median annual relative humidity outdoors and estimates for the Cartoon Gallery from UKCP09. The error bars show the upper and lower quartiles.

temperature from observations and the estimated indoor temperature. The dispersion in the values is displayed as an error bar indicating the lower and upper quartiles. Medians and quartiles have been adopted in preference to means and standard deviation as the former are more robust when the data are not normally distributed. The UKCP09 indoor and outdoor predictions for the future are also shown in Figure 1. Here the medians of the 3000 annual means and lower and upper quartiles are shown. The transfer function adopted also has an error, but it can explain more than $90 \%$ of the variance and give daily indoor predictions that show satisfying agreement with probable error at the $95 \%$ confidence interval of just under $\pm 2{ }^{\circ} \mathrm{C}$ [14]. The indoor temperatures are somewhat higher than outdoor temperatures through solar gain. The difference gets smaller in the future because of the ability of the interiors to buffer against temperature extremes.

The relative humidity indoors and outdoors for the 30-year periods centred at various times from 1975 to 2085 is shown in the lower right of Figure 1. We can see that despite drier conditions outdoors the relative humidity indoors is rather stable because the increase in temperature is not as great indoors as outdoors. There is the potential for seasonal shifts in the Cartoon Gallery with drier summer conditions indoors and slightly damper winters [14].

Indoor formic and acetic acid concentrations can be estimated theoretically from degassing rates as a 
function of temperature. The estimates into the future have made the assumption that the release rate is dependent on the vapour pressure of the acid. This assumption has a number of problems: (i) it assumes that the acid is not being depleted in the wood, but often wood takes a very long time to lose all the carboxylic acid and (ii) it does allow for changes in the moisture content of the wood or its $\mathrm{pH}$. The vapour pressure of formic (pFo) and acetic (pAc) acid, in pascals was estimated in terms of the Antoine equation as [20]:

$$
\begin{aligned}
& \mathrm{pFO}=133.332 * 10^{(8.779-2162.39 /(\mathrm{T}+273.15))} \\
& \mathrm{pAC}=133.332 * 10^{(8.502-2177.1 /(\mathrm{T}+273.15))}
\end{aligned}
$$

where $\mathrm{T}$ is the temperature of the room $\left({ }^{\circ} \mathrm{C}\right)$. The initial estimates made no assumption about the importance of the moisture content of the wood. The daily partial pressure was calculated for the indoor temperatures and averaged for each year as estimated from HadCET and for the 3000 annual predictions from UKCP09. The medians and quartiles for the annual mean partial pressure of the carboxylic acids are shown in Figure 2.

Indoor concentrations of acetic acid in the Cartoon Gallery were estimated from emission factors combined with the measured dimensions of the room and the wood surface areas. This, combined with the air change rate has enabled us to predict the concentrations of acetic acid in the Cartoon Gallery as about close to 100 $\mu \mathrm{g} \mathrm{m} \mathrm{m}^{-3}$. (room volume $108 \mathrm{~m}^{3}$, wood $54 \mathrm{~m}^{2}$, air change

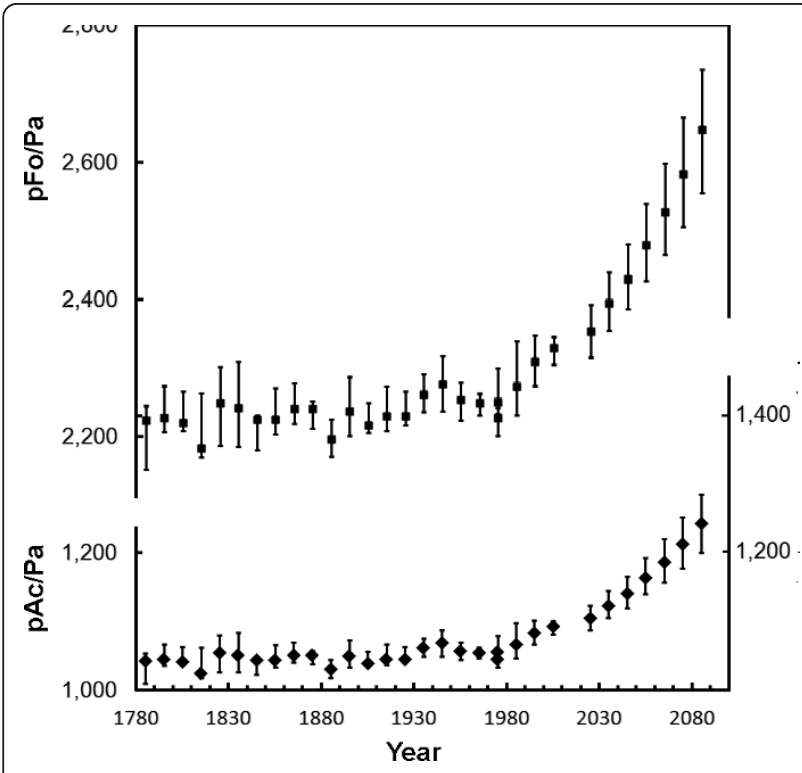

Figure 2 Median of the annual partial pressures of formic and acetic acid at temperatures predicted for the Cartoon Gallery. The error bars show the upper and lower quartiles.
$2 \mathrm{hr}^{-1}$, emission rate from wood $\left.400 \mu \mathrm{g} \mathrm{m}^{-2} \mathrm{hr}^{-1}\right)$. One would presume that this indoor concentration would increase in proportion to the mean partial pressure, so increases are to be expected over the coming century, so we might predict about $120 \mu \mathrm{g} \mathrm{m}^{-3}$. Thickett and Lankester [21] have shown that measured concentrations of acetic acid tend to be higher in summer in museum cases, which supports the importance of temperature in controlling carboxylic acid concentrations. Our estimates presume that the acid in the wood is not depleted and there are such large quantities that this takes place only slowly. As changes in humidity are rather small these seem unlikely to alter the emission rate in the Cartoon Gallery over the next century.

Similar calculations might be attempted for carbonyl sulfide, but they are likely to show much the same increase (perhaps 20\% increase for a few degrees rise in temperature) that was predicted for the carboxylic and acetic acids. However, it is possible that the carbonyl sulfide will deplete relatively quickly from wool [9]. In the case of formaldehyde the potential heritage impact is less clear given that the subsequent oxidation is likely to affect the rate of damage the gas imposes on materials. The changes in carbonyls determined for historic rooms are also likely to be reflected in the changes in these compounds in the interiors of exhibition cases, but here lower ventilation rates mean that concentrations can be even higher.

\section{Conclusion}

Although the socio-economic significance of climate change is widely recognized, the potential impacts on our cultural heritage have not always been well studied. Heritage is not explicitly mentioned in the outputs of the Intergovernmental Panel on Climate Change. Despite this there have been a number of European Commission funded projects that have examined climate change and heritage. Focus has often been on the outdoor environment, although recent projects such as Climate for Culture and the UK projects Preparing Collections for Climate Change and Collections Demography have looked at the propagation of future climate change indoors.

The results from this investigation of the indoor environment give guidance for collection managers in planning strategies to reduce the impact of long-term climate change and thus preserve our heritage for future generations. The projections here would suggest that where there are historic rooms and collections that are vulnerable, risks to carbonyls (especially the acids) may increase if indoor temperatures rise. There needs to be continued care over the choice of materials for use within cases, especially where temperatures rise substantially. This might also be mitigated by increased air 
purification. Future work could explore improved estimates of indoor carbonyls, not only with better models for the projections of indoor climate, but also making use of thermodynamic models to estimate the relationship between relative humidity (and of course water activity) and the partial pressure of acetic acid. They might also examine the impact of future ozone and other oxidants on the heritage impact of formaldehyde.

\section{Acknowledgements}

Funding for part of this work was provided through the Science and Heritage programme to the Collections Demography project jointly funded by the Arts and Humanities Research Council (AHRC) and the Engineering and Physical Sciences Research Council (EPSRC).

\section{Authors' contributions}

PB undertook the calculations and wrote the initial draft to the MS. CMG reviewed the literature on carboxylic acids and how their indoor concentration might be estimated. All authors read and approved the final manuscript.

\section{Competing interests}

The authors declare that they have no competing interests.

Received: 1 February 2012 Accepted: 22 March 2012

Published: 22 March 2012

\section{References}

1. Volent $P$, Baer NS: Volatile amines used as corrosion inhibitors in museum humidification systems. Int J Museum Manage Curatorship 1985, 4:359-364.

2. Schieweck A, Delius W, Siwinski N, Vogtenrath W, Genning C, Salthammer T: Occurrence of organic and inorganic biocides in the museum environment. Atmos Environ 2007, 41:3266-3275.

3. Giebelhausen M: Museum Architecture: a brief history in Macdonald, S. A Companion to Museum Studies Blackwell Oxford; 2006, 223-244.

4. Moyes J: Oak floors 'damaging art' at Tate Modern. The Independent (London, England); 2000.

5. Hatchfield P, Carpenter J: Formaldehyde: How great is the danger to museum collections? Harvard University Art Museums: Center for Conservation and Technical Studies; 1987.

6. Raychaudhuri MR, Brimblecombe P: Formaldehyde oxidation and lead corrosion. Stud Conservat 2000, 45:226-232.

7. Brimblecombe P: Environmental health and safety in buildings. In Materials for Energy Efficiency and Thermal Comfort in Buildings. Edited by: Hall M. Cambridge: Woodhead Publishing; 2010:148-172.

8. Ankersmit HA, Tennent NH, Watts SF: Hydrogen sulfide and carbonyl sulfide in the museum environment. Atmos Environ 2005, 39:695-707.

9. Brimblecombe P, Shooter D, Kaur A: Wool and reduced sulfur gases in museum air. Stud Conserv 1992, 37:53-60.

10. Brimblecombe P: The composition of museum atmospheres. Atmos Environ 1990, 24B:1-8.

11. Wang S, Kong L, An Z, Chen J, Wu L, Zhou X: An improved Oddy test using metal films. Stud Conserv 2011, 56:138-153.

12. Camuffo D, Bertolin C, Brimblecombe P, Amore C, Bergonzini A: Simulated relative humidity cycles experienced by historical buildings in past centuries. Journal of Cultural Heritage 2012, submitted.

13. Lankester $P$, Brimblecombe P: Future thermohygrometric climate within historic houses. J Cult Herit 2012, 13:1-6.

14. Lankester $\mathrm{P}$, Brimblecombe $\mathrm{P}$ : The impact of future climate on historic interiors. Science of the Total Environment 2012, 417-418C:248-254.

15. Xiong J, Zhang Y: Impact of temperature on the initial emittable concentration of formaldehyde in building materials: experimental observation. Indoor Air 2010, 20:523-529.

16. Meleux F, Solmon F, Giorgi F: Increase in summer European ozone amounts due to climate change. Atmos Environ 2007, 41:7577-7587.
17. Parker DE, Legg TP, Folland CK: A new daily central England temperature series, 1772-1991. Int J Clim 1992, 12:317-342.

18. Brimblecombe P, Lankester P: Long term changes in climate and insect damage in historic houses. Studies in Conservation, submitted.

19. Jones PD, Kilsby CG, Harpham C, Glenis V, Burton A: UK Climate Projections Science Report: Projections of Future Daily Climate for the UK from the Weather Generator UK: University of Newcastle; 2009.

20. Weast, handbook of Chemistry and physica. Chemical Rubber Co. Cleveland Ohio; 1970/71.

21. Thickett $D$, Lankester P: Critical knowledge gaps in environmental risk assessment and prioritising research. Collections, submitted.

doi:10.1186/1752-153X-6-21

Cite this article as: Brimblecombe and Grossi: Carbonyl compounds indoors in a changing climate. Chemistry Central Journal 2012 6:21.

\section{Publish with ChemistryCentral and every scientist can read your work free of charge \\ "Open access provides opportunities to our colleagues in other parts of the globe, by allowing anyone to view the content free of charge." W. Jeffery Hurst, The Hershey Company. \\ - available free of charge to the entire scientific community - peer reviewed and published immediately upon acceptance \\ - cited in PubMed and archived on PubMed Central \\ - yours - you keep the copyright \\ Submit your manuscript here: \\ http://www.chemistrycentral.com/manuscript/<smiles>c1ccccc1</smiles> Chemistry Central}

